Research Article

\title{
Determination of Residual Stress and Design of Process Parameters for Composite Cylinder in Filament Winding
}

\author{
Chao Kang $\left(\mathbb{D},{ }^{1}\right.$ Yaoyao Shi, ${ }^{1}$ Bo Deng, ${ }^{1}$ Tao Yu, ${ }^{1}$ and Pengcheng Sun ${ }^{2}$ \\ ${ }^{1}$ The Key Laboratory of Contemporary Design and Integrated Manufacturing Technology, Ministry of Education, \\ Northwestern Polytechnical University, Xi'an, Shaanxi 710072, China \\ ${ }^{2}$ Institute of Applied Optics, Xi'an, Shaanxi 710065, China \\ Correspondence should be addressed to Chao Kang; kaochao_017@163.com
}

Received 23 November 2017; Accepted 17 January 2018; Published 29 March 2018

Academic Editor: Fabrizio Sarasini

Copyright $(2) 2018$ Chao Kang et al. This is an open access article distributed under the Creative Commons Attribution License, which permits unrestricted use, distribution, and reproduction in any medium, provided the original work is properly cited.

\begin{abstract}
As there is increasing usage of composite components with a closed-end shape, filament winding technology has been applied extensively in engineering practice. However, the residual stresses are readily caused by process parameters in composite manufacturing process. Hence, it is necessary to design the reasonable process parameters for obtaining the expected residual stresses. This study proposed a reverse derivation method to design the winding tension based on the residual stress model of the composite cylinder. To analyze the development of residual stresses, the thermal deformation behavior and a micromechanics model of resin shrinkage are considered to calculate thermal strains and instantaneous shrinkage strains of the hoop wound cylinder during the curing process. Combining the contribution of winding tension to the stresses, the simple model of residual stresses is established based on the superposition principle. Then inversely solving the analytic model, the design method of winding tension is illustrated to guarantee that the hoop wound cylinder with an inner liner has a uniform residual hoop stress. The model accuracy of residual stresses is validated by the destructive slitting experiment. The result indicates that the present model can be used to estimate the residual stresses and design the winding tension for the hoop wound cylinder.
\end{abstract}

\section{Introduction}

Advanced resin matrix composites have been widely used in aviation industry due to the special features such as high strength and stiffness, long life, and lightweight $[1,2]$. As a kind of manufacturing process, filament winding was proposed to fabricate composite components. With the increased applications of composite wound components, there has been a growing desire for composites parts such as missile cones, rocket hull, pressure vessel, and other engineering fields $[3,4]$. However, the residual stresses of composite part will be generated inevitably due to winding tension, thermal expansions, and chemical shrinkage reaction during the manufacturing process. It is well known that the high residual stresses will not only cause the microcracks and the eventual delamination between layers but also significantly reduce the ability to resist load [5-7]. Since the residual stresses of composite highly depend on the process parameters, it is necessary to investigate the stress development of composite components during the fabricating process.

Recently, a series of theoretical models have been developed for studying the stress state of the composite cylinder. Several researchers have previously investigated the development of stress induced by winding tension during the winding process based on the finite difference method and other numerical methods [8-10]. Nevertheless, the curing process is also a dominant factor which affects the residual stress distribution of composite during the whole manufacturing process. Therefore, based on the assumption of micromechanics, the thermal and chemical shrinkage stress models of the composite cylinder had been established during the curing process [11-14]. To accurately determine the residual stress model and predict the stress profile, some authors considered the coupling effects of winding tension and cure parameters on the residual stresses [15-18].

Compared with how to predict the residual stresses, designing process parameters to satisfy requirement of 


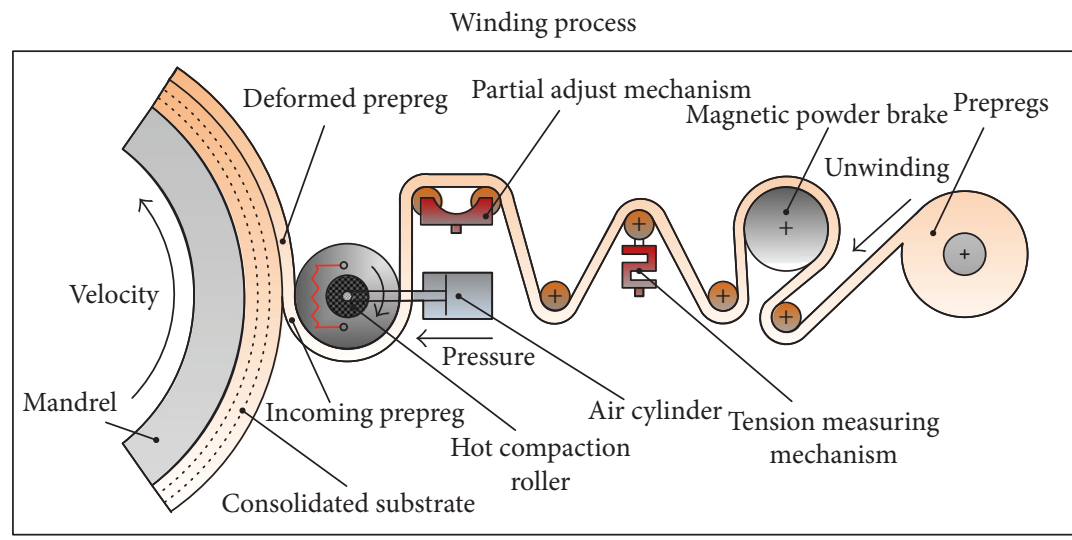

(a)

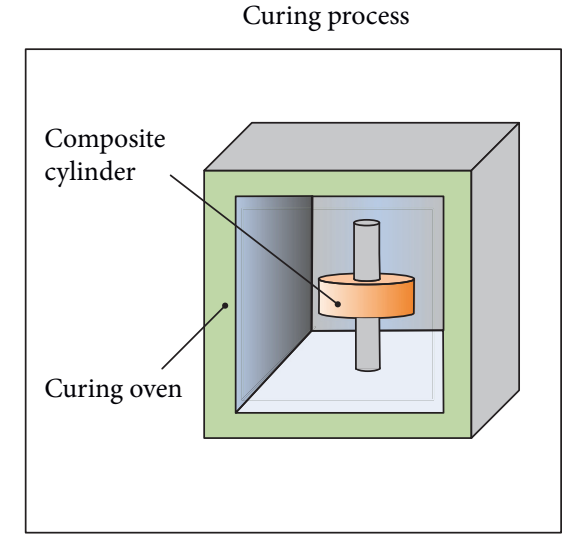

(b)

FIgURE 1: Manufacturing process of the composite wound cylinder. (a) Winding process. (b) Curing process.

residual stresses has become more meaningful. Kim et al. [19] and Lee et al. [20] proposed a smart cure method to reduce the residual stresses in the thick wound composite cylinder by using finite element method. Ren et al. addressed a finite element strategy for simulating the winding process of the wound vessel with a metal liner. Then, the iterative search method was established to calculate the initial winding tension of any winding layer for ensuring the residual hoop stress uniform [21]. Wu and Zhang adopted the neural network method to determine the initial winding tension for ensuring the residual hoop stress of each layer consistency [22]. Xu et al. studied the residual hoop stress caused by winding tension and temperature. Based on the mix-mode method of elastic modulus, the design method of process parameters was addressed for the composite cylinder with a hot core [23].

As can be observed from the previous studies, the residual stresses of composite component have received tremendous attention. Besides, how to design process parameters has also been a crucial issue. However, it is noticed that most studies about the parametric design only involved the winding process or the curing process. Although a few works considered the whole manufacturing process, their models assumed composite as the isotropy material [23]. In order to improve the accuracy of the model of residual stresses, the wound cylinder is assumed as the transversely isotropic material in this article. Adopting the plane stress assumption and the micromechanics model, the analytic model of residual stresses for hoop wound cylinder with an inner liner is established by considering the shrinkage stress and thermal stress. Subsequently, the residual stresses of composite cylinder after mandrel removal are determined according to the stress equilibrium. Then, the destructive slitting experiment is performed to measure the residual stresses. The results show that the experimental data are consistent with the simulated value. Moreover, based on the theoretical model, the design method of the winding tension is proposed to ensure that the composite cylinder with an inner liner has a uniform residual hoop stress through the filament wound section.

\section{Filament Winding Process}

The residual stresses of wound cylinder depend on the manufacturing parameters and material characteristics [15]. Especially the stress state of composite cylinder is mainly affected by winding tension and curing processing parameters. Figure 1 displays the general manufacturing process of the fabricating composite component. The whole process includes the winding process and curing process. In the winding process, the prepreg tape is tightened through a magnetic powder brake controlled by a closed-loop system. Then, the tape is heated and compressed by the hot compaction roller. Subsequently, the hot-melted prepreg tape is wrapped onto the rotating mandrel. In the curing process, the degree of curing varies as the temperature of composite component changes. The whole manufacturing process is incomplete until the curing reaction is finished, and the temperature of composite component drops to the environment temperature.

\section{Establishment of Residual Stresses}

Through the above description of the prepreg tape winding process, it can be seen that the key parameters include winding tension, winding temperature, and pressure. Among these parameters, the winding tension affects the residual stresses significantly. The temperature can cause the thermal stress when the prepreg tape is heated by the hot compaction roller in the winding process. However, the thermal stress is released rapidly due to the viscous flow state of resin. Although the pressure is applied to improve the interface bonding strength, the pressure will be zero when the hot compaction roller gets back. Thus, assuming the residual stress induced by pressure will not be taken into account. In the curing process, it is found that the temperature gradient leads to thermal stress, and the shrinkage of composite volume causes chemical shrinkage stress [24]. Therefore, the influences of winding temperature and pressure on residual stresses can be ignored. The residual stresses, namely, the final stress state of the composite cylinder, can be derived according to the procedure shown in Figure 2. The first step is 


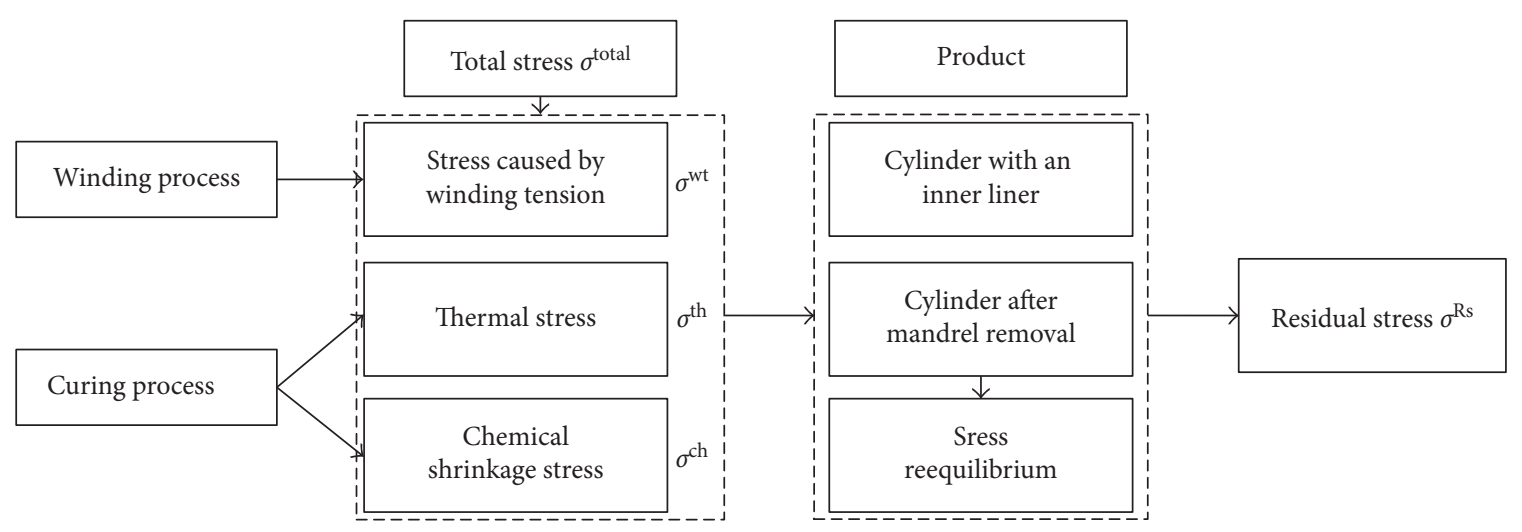

FIGURE 2: The solving procedure of residual stresses.

to obtain the total stress of composite with a mandrel in the filament winding process. It can be expressed as

$$
\sigma^{\text {total }}=\sigma^{\mathrm{wt}}+\sigma^{\mathrm{th}}+\sigma^{\mathrm{ch}}
$$

where $\sigma^{\text {total }}$ is the total stress of composite with mandrel and $\sigma_{i}^{\mathrm{wt}}$ is the stress caused by the winding process. $\sigma_{i}^{\text {th }}$ and $\sigma_{i}^{\mathrm{ch}}$ represent the thermal stress caused by temperature gradient and the chemical shrinkage stress induced by the curing reaction, respectively.

3.1. Stress Caused by the Winding Process. In this study, the following assumptions should be addressed to simplify the analysis: (a) the plane stress hypothesis is adopted during the modeling of the whole manufacturing process, (b) layers are visualized as discrete rings, and the stress for each layer is obtained based on the superposition principle, (c) the composite modulus is obtained based on the basic mixing rule in the modeling of the whole manufacturing process, and (d) the mandrel is made of an isotropic and linear elastic material.

In the winding process, consider a thick-walled cylinder with an inner radius of $b$, outer radius of $r_{j}$ which represents the current winding layer, and a mandrel with an inner radius of $a$. The cylinder is treated as a transversely isotropic material under an axially symmetric load. As shown in Figure 3, the pressure force induced by winding tension imposes on the outer surface of the composite cylinder. Moreover, the stress state of the composite cylinder varies as the incoming prepreg tape is continuously wrapped on the substrate.

3.1.1. Mandrel Generalized Stiffness. According to the thick cylinder theory, the relationship between displacement and radial stress of mandrel can be written as

$$
\left[\begin{array}{c}
u_{\mathrm{Mr}} \\
\sigma_{\mathrm{Mr}}
\end{array}\right]=\left[\begin{array}{cc}
r & \frac{1}{r} \\
\frac{E_{M}}{1-v_{M}} & -\frac{E_{M}}{1+v_{M}} \frac{1}{r^{2}}
\end{array}\right]\left[\begin{array}{l}
A \\
B
\end{array}\right],
$$

where $u_{\mathrm{Mr}}$ and $\sigma_{\mathrm{Mr}}$ denote the displacement and stress of mandrel in the radial direction, $v_{M}$ is Poisson's ratio

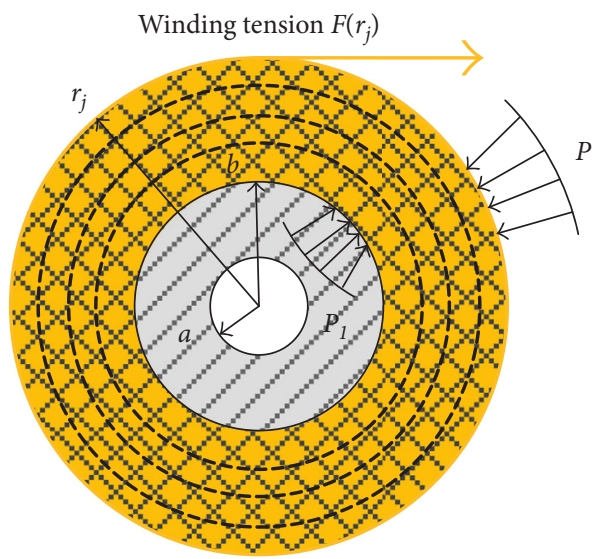

FIgURE 3: Cross-sectional model of the composite cylinder during the winding process.

of mandrel, $A$ and $B$ are constants, and $r$ is the radius of mandrel.

Based on the winding process, the boundary conditions on the internal and external surfaces of mandrel can be expressed as

$$
\begin{array}{ll}
\sigma_{\mathrm{Mr}}=0, & r=a \\
\sigma_{\mathrm{Mr}}=-P_{1}, & r=b,
\end{array}
$$

where $a$ and $b$ are the internal and external radius of mandrel and $P_{1}$ is the external pressure.

Here, the generalized stiffness $K$ is introduced in the radial direction, and it is defined as [25]

$$
K=\frac{\sigma_{\mathrm{Mr} \mid r=b}}{u_{\mathrm{Mr} \mid r=b}}
$$

Substituting (2) into boundary conditions (3) and introducing the result and (2) into (4a), the generalized stiffness can be derived as

$$
K=\frac{\left(b^{2}-a^{2}\right) E_{M}}{b\left[b^{2}\left(1-v_{M}\right)+a^{2}\left(1+v_{M}\right)\right]} .
$$

3.1.2. Stress of the Composite Cylinder. For the composite cylinder, the strains can be defined as 


$$
\begin{aligned}
& \varepsilon_{r}=\frac{d u_{r}}{d r}, \\
& \varepsilon_{\theta}=\frac{u_{r}}{r},
\end{aligned}
$$

where $u_{r}$ is the radial displacement and $\varepsilon_{r}$ and $\varepsilon_{\theta}$ represent the radial and hoop strains, respectively.

The corresponding linear constitutive equations of the thick composite cylinder are

$$
\left[\begin{array}{l}
\varepsilon_{r} \\
\varepsilon_{\theta}
\end{array}\right]=\left[\begin{array}{cc}
\frac{1}{E_{r}} & -\frac{v_{\theta}}{E_{\theta}} \\
-\frac{v_{r}}{E_{r}} & \frac{1}{E_{\theta}}
\end{array}\right]\left[\begin{array}{l}
\sigma_{r} \\
\sigma_{\theta}
\end{array}\right],
$$

where $E_{r}$ and $E_{\theta}$ are the radial and hoop elastic modulus, $\sigma_{r}$ and $\sigma_{\theta}$ represent the stresses in the radial and hoop direction, and $v_{r}$ and $v_{\theta}$ denote Poisson's ratios of radial and hoop.

The mechanical equilibrium equation is

$$
\frac{d \sigma_{r}}{d r}+\frac{\sigma_{r}-\sigma_{\theta}}{r}=0
$$

The following equation in $u_{r}$ is derived by substituting (5) into (6) and substituting the obtained relationship into (7)

$$
u_{r}^{\prime \prime}+\frac{1}{r} u_{r}^{\prime}-\frac{\beta^{2}}{r^{2}} u_{r}=0
$$

where $\beta^{2}=E_{\theta} / E_{r}$.

The solution of the displacement can be given by

$$
u_{r}=c_{1} r^{\beta}+c_{2} r^{-\beta}
$$

where $c_{1}$ and $c_{2}$ are determined by the boundary conditions.

Inverting (6) and introducing (9) and (5) into it, the stresses of the composite cylinder are derived as

$$
\begin{aligned}
& \sigma_{r}=c_{1} S_{1} r^{\beta-1}-c_{2} S_{2} r^{-\beta-1}, \\
& \sigma_{\theta}=c_{1} S_{3} r^{\beta-1}+c_{2} S_{4} r^{-\beta-1} .
\end{aligned}
$$

The coefficients are derived from the following equations:

$$
\begin{aligned}
& S_{1}=\frac{\beta+v_{\theta}}{1-v_{r} v_{\theta}} E_{r}, \\
& S_{2}=\frac{\beta-v_{\theta}}{1-v_{r} v_{\theta}} E_{r}, \\
& S_{3}=\frac{1+\beta v_{r}}{1-v_{r} v_{\theta}} E_{\theta}, \\
& S_{4}=\frac{1-\beta v_{r}}{1-v_{r} v_{\theta}} E_{\theta} .
\end{aligned}
$$

The boundary conditions on the internal and external surfaces are given as follows:

$$
\begin{array}{ll}
\sigma_{r}=-P_{1}, & r=b \\
\sigma_{r}=-P, & r=r_{j} .
\end{array}
$$

Inverting (4a) and introducing the result into the continuity conditions, $\sigma_{r}=\sigma_{\mathrm{Mr}}=-P_{1}$ and $u_{r}=u_{\mathrm{Mr}}$ at $r=b$. Therefore, (12a) can be rewritten as

$$
\begin{aligned}
& \sigma_{r}=K \cdot u_{r}, \quad r=b \\
& \sigma_{r}=-P, \quad r=r_{j} .
\end{aligned}
$$

By substituting (9) and (10a) into the above boundary conditions, (12b) leads to

$$
\begin{aligned}
& c_{1}=-\frac{H_{2}\left(r_{j} / b\right)^{2 \beta}}{H_{1} S_{2}+H_{2} S_{1}\left(r_{j} / b\right)^{2 \beta}}\left(\frac{1}{r_{j}^{\beta-1}}\right) P, \\
& c_{2}=\frac{H_{1} r_{j}^{\beta+1}}{H_{1} S_{2}+H_{2} S_{1}\left(r_{j} / b\right)^{2 \beta}} P,
\end{aligned}
$$

where $H_{1}=K b-S_{1}$ and $H_{2}=K b+S_{2}$.

Substituting (13a) and (13b) into (10a) and (10b) yields

$$
\begin{gathered}
\sigma_{r}=-\frac{H_{1} S_{2}+H_{2} S_{1}(r / b)^{2 \beta}}{H_{1} S_{2}+H_{2} S_{1}\left(r_{j} / b\right)^{2 \beta}}\left(\frac{r}{r_{j}}\right)^{-\beta-1} P, \\
\sigma_{\theta}=\frac{H_{1} S_{4}-H_{2} S_{3}(r / b)^{2 \beta}}{H_{1} S_{2}+H_{2} S_{1}\left(r_{j} / b\right)^{2 \beta}}\left(\frac{r}{r_{j}}\right)^{-\beta-1} P .
\end{gathered}
$$

Based on the superposition principle, the total hoop stress of the $i$ th layer in the composite cylinder is the sum of stresses caused by all of layers wrapped from the $i$ th to $n$th layer after the winding process is completed. Thus, the final hoop stress of the composite cylinder induced by winding tension can be established as follows:

$$
\begin{aligned}
\sigma_{\theta}^{\mathrm{wt}}\left(r_{i}, r_{n}\right) & =\frac{F\left(r_{i}\right)}{h}+\sigma_{\theta}(i, i+1)+\cdots+\sigma_{\theta}(i, n) \\
& =\frac{F\left(r_{i}\right)}{h}+\sum_{j=i+1}^{n} \sigma_{\theta}(i, j),
\end{aligned}
$$

where $h$ is the thickness of the prepreg tape and $F\left(r_{i}\right)$ denotes the winding tension per width for the $i$ th layer.

Since the thickness of the prepreg tape is too thin, the numerical integration method is adopted to simplify (15), and then (14b) is substituted into it. The hoop stress of the composite cylinder can be derived as

$$
\sigma_{\theta}^{\mathrm{wt}}(x)=\frac{1}{h}\left[F(x)+\left(H_{1} S_{4}-H_{2} S_{3}(x)^{2 \beta}\right)(x)^{-\beta-1} \int_{x}^{m} \frac{\xi^{\beta} F(\xi)}{H_{1} S_{2}+H_{2} S_{1} \xi^{2 \beta}} d \xi\right],
$$


where $\xi$ is the dummy variable of integration, $m=r_{n} / b$, and $x=r_{i} / b$.
Based on the superposition principle and combining (14a), the final radial stress of the composite cylinder can be given as

$$
\sigma_{r}^{\mathrm{wt}}(x)=-\frac{1}{h}\left[H_{1} S_{2}+H_{2} S_{1}(x)^{2 \beta}\right](x)^{-\beta-1} \int_{x}^{m} \frac{\xi^{\beta} F(\xi)}{H_{1} S_{2}+H_{2} S_{1} \xi^{2 \beta}} d \xi
$$

3.2. Stresses Induced by the Curing Process. After the composite cylinder is placed into the cure oven, the temperature of the composite cylinder rises gradually. Then, the degree of resin curing changes as the curing reaction occurs. A general formula to calculate the degree of cure is given as follows [26]:

$$
\alpha=1-\left[1-\operatorname{At}(1-n) \exp \left(-\frac{E_{a}}{R T}\right)\right]^{1 /(1-n)},
$$

where $A$ is the preexponential constant, $t$ is the time, $E_{a}$ is the activated energy, $n$ is the reaction progression, and $R$ and $T$ are the gas constant and temperature, respectively.

In addition, the stiffness of the resin significantly depends on the degree of cure $\alpha$. The expression for resin modulus can be written as [24]

$$
E_{c}=(1-\alpha) E_{c}^{0}+\alpha E_{c}^{\infty}
$$

where $E_{c}^{0}$ and $E_{c}^{\infty}$ are the initial and fully cured resin modulus. Here, $E_{c}^{0}$ is generally assumed to be $E_{c}^{\infty} / 1000$ as an approximation [24, 27].

3.2.1. Thermal Stress. In the curing process, assume that the thermal stress just occurs in the cooling stage. To simplify the thermal stress analysis, the temperature difference between cure temperature and ambient condition is assumed as uniform. Thus, the resin is fully cured, and the resin modulus is $E_{c}^{\infty}$. Effective coefficients of thermal expansion in the radial and hoop directions are calculated using the micromechanics model as [24]

$$
\begin{aligned}
a_{r}= & \frac{a_{f} E_{f} V_{f}+a_{c} E_{c}^{\infty}\left(1-V_{f}\right)}{E_{f} V_{f}+E_{c}^{\infty}\left(1-V_{f}\right)}, \\
a_{\theta}= & \left(a_{f}+v_{f} a_{f}\right) V_{f}+\left(a_{c}+v_{c} a_{c}\right)\left(1-V_{f}\right) \\
& -\left(v_{f} V_{f}+v_{c}\left(1-V_{f}\right)\right) a_{r} .
\end{aligned}
$$

The linear plane stress-strain relationship is adopted as follows:

$$
\left[\begin{array}{c}
\varepsilon_{r}^{\text {th }} \\
\varepsilon_{\theta}^{\text {th }}
\end{array}\right]=\left[\begin{array}{ccc}
\frac{1}{E_{r}} & -\frac{v_{\theta}}{E_{\theta}} & a_{r} \\
-\frac{v_{r}}{E_{r}} & \frac{1}{E_{\theta}} & a_{\theta}
\end{array}\right]\left[\begin{array}{c}
\sigma_{r}^{\text {th }} \\
\sigma_{\theta}^{\text {th }} \\
\Delta T
\end{array}\right],
$$

where $a_{r}$ and $a_{\theta}$ are the radial and hoop coefficients of thermal expansion and $\Delta T$ is the difference between the maximum curing temperature and room temperature.

The corresponding strain-displacement relationships are

$$
\begin{gathered}
\varepsilon_{r}^{\mathrm{th}}=\frac{d u_{r}^{\mathrm{th}}}{d r}, \\
\varepsilon_{\theta}^{\mathrm{th}}=\frac{u_{r}^{\mathrm{th}}}{r} .
\end{gathered}
$$

The equilibrium equation is

$$
\frac{d \sigma_{r}^{\mathrm{th}}}{d r}+\frac{\sigma_{r}^{\mathrm{th}}-\sigma_{\theta}^{\mathrm{th}}}{r}=0
$$

The following equation in $u_{r}^{\text {th }}$ is derived by substituting (20) into (21) and then substituting the obtained relationship into (22):

$$
\left(u_{r}^{\text {th }}\right)^{\prime \prime}+\frac{1}{r}\left(u_{r}^{\text {th }}\right)^{\prime}-\frac{\beta^{2}}{r^{2}} u_{r}^{\text {th }}=\frac{1}{r} \Delta T \frac{f_{1}-f_{2}}{E_{r}}
$$

where $f_{1}=\left(v_{\theta} a_{\theta}+a_{r}\right) E_{r}$ and $f_{2}=\left(v_{r} a_{r}+a_{\theta}\right) E_{\theta}$.

The solution of displacement can be given by

$$
u_{r}^{\text {th }}=a_{1} r^{\beta}+a_{2} r^{-\beta}+\frac{f_{1}-f_{2}}{E_{r}-E_{\theta}} \Delta T \cdot r,
$$

where $a_{1}$ and $a_{2}$ are the constants determined by boundary conditions.

The boundary conditions on internal and external surfaces are given by

$$
\begin{aligned}
& \sigma_{r}^{\text {th }}=K \cdot u_{r}^{\text {th }}, \quad r=b \\
& \sigma_{r}^{\text {th }}=0, \quad r=r_{n} .
\end{aligned}
$$

Combining (20), (21), (24), and (25), the thermal stress of each layer can be determined as 


$$
\begin{aligned}
\sigma_{r}^{\text {th }}(x)= & \frac{S_{6}}{H_{1} S_{2}+H_{2} S_{1}(m)^{2 \beta}}\left(\frac{x}{m}\right)^{-\beta-1}\left[S_{1} S_{2}(m)^{\beta-1}\left(\frac{x}{m}\right)^{2 \beta}-H_{1} S_{2}-S_{1} S_{2}(m)^{\beta-1}-H_{2} S_{1}(x)^{2 \beta}\right] \\
& +\frac{b K \Delta T\left(f_{1}-f_{2}\right)}{\left[H_{1} S_{2}+H_{2} S_{1} m^{2 \beta}\right]\left(E_{r}-E_{\theta}\right)}(x)^{-\beta-1}\left[\left(\frac{x}{m}\right)^{-2 \beta}-1\right]+S_{6}, \\
\sigma_{\theta}^{\text {th }}(x)= & -\frac{S_{6}}{H_{1} S_{2}+H_{2} S_{1}(m)^{2 \beta}}\left(\frac{x}{m}\right)^{-\beta-1}\left[-H_{1} S_{4}-S_{1} S_{4}(m)^{\beta-1}+H_{2} S_{3}(x)^{2 \beta}-S_{2} S_{3}(m)^{\beta-1}\left(\frac{x}{m}\right)^{2 \beta}\right] \\
& -\frac{b K \Delta T\left(f_{1}-f_{2}\right)}{\left[H_{1} S_{2}+H_{2} S_{1} m^{2 \beta}\right]\left(E_{r}-E_{\theta}\right)}(x)^{-\beta-1}\left[S_{1} S_{4}\left(\frac{x}{m}\right)^{-2 \beta}+S_{2} S_{3}\right]+S_{5} .
\end{aligned}
$$

The parameters are defined by the following equations:

$$
\begin{aligned}
& S_{5}=\frac{f_{1} \beta^{2}\left(1+v_{r}\right)-f_{2}\left(1+\beta^{2} v_{r}\right)}{\left(1-v_{r} v_{\theta}\right)\left(1-\beta^{2}\right)} \Delta T, \\
& S_{6}=\frac{f_{1}\left(v_{\theta}+\beta^{2}\right)-f_{2}\left(1+v_{\theta}\right)}{\left(1-v_{r} v_{\theta}\right)\left(1-\beta^{2}\right)} \Delta T .
\end{aligned}
$$

3.2.2. Chemical Shrinkage Stress. The resin shrinkage mainly depends on the degree of cure and the total volumetric shrinkage of the cured resin. Since the resin is a kind of isotropic material, the contraction for a unit cell in resin is uniform in each direction. The incremental shrinkage strain of resin can be calculated as follows [24]:

$$
\Delta \varepsilon_{c}=\sqrt[3]{1+\Delta \alpha \cdot V_{\mathrm{sh}}}-1
$$

where $\Delta \alpha$ is the increment of degree of curing with temperature gradient and $V_{\text {sh }}$ is the volume shrinkage ratio.

Effective chemical shrinkage strains in the composite are calculated according to the micromechanics model. The incremental shrinkage strains of composite can be calculated as follows [24]:

$$
\begin{aligned}
\Delta \varepsilon_{\theta}^{\mathrm{ch}} & =\frac{\Delta \varepsilon_{c} E_{c}\left(1-V_{f}\right)}{E_{f} V_{f}+E_{c}\left(1-V_{f}\right)}, \\
\Delta \varepsilon_{r}^{\mathrm{ch}} & =\left(\Delta \varepsilon_{c}+v_{c} \Delta \varepsilon_{c}\right)\left(1-V_{f}\right)-\left(v_{r} V_{f}+v_{c}\left(1-V_{f}\right)\right) \Delta \varepsilon_{\theta}^{\mathrm{ch}} .
\end{aligned}
$$

Thus, analogously to the method for calculating the thermal stress, the chemical shrinkage stress can be determined as

$$
\begin{aligned}
\Delta \sigma_{r}^{\mathrm{ch}}(x)= & \frac{S_{8}}{H_{1} S_{2}+H_{2} S_{1}(m)^{2 \beta}}\left(\frac{x}{m}\right)^{-\beta-1}\left[S_{1} S_{2}(m)^{\beta-1}\left(\frac{x}{m}\right)^{2 \beta}-H_{1} S_{2}-S_{1} S_{2}(m)^{\beta-1}-H_{2} S_{1}(x)^{2 \beta}\right] \\
& +\frac{b K\left(g_{1}-g_{2}\right)}{\left[H_{1} S_{2}+H_{2} S_{1} m^{2 \beta}\right]\left(E_{r}-E_{\theta}\right)}(x)^{-\beta-1}\left[\left(\frac{x}{m}\right)^{-2 \beta}-1\right]+S_{8}, \\
\Delta \sigma_{\theta}^{\mathrm{ch}}(x)= & -\frac{S_{8}}{H_{1} S_{2}+H_{2} S_{1}(m)^{2 \beta}}\left(\frac{x}{m}\right)^{-\beta-1}\left[-H_{1} S_{4}-S_{1} S_{4}(m)^{\beta-1}+H_{2} S_{3}(x)^{2 \beta}-S_{2} S_{3}(m)^{\beta-1}\left(\frac{x}{m}\right)^{2 \beta}\right] \\
& -\frac{b K\left(g_{1}-g_{2}\right)}{\left[H_{1} S_{2}+H_{2} S_{1} m^{2 \beta}\right]\left(E_{r}-E_{\theta}\right)}(x)^{-\beta-1}\left[S_{1} S_{4}\left(\frac{x}{m}\right)^{-2 \beta}+S_{2} S_{3}\right]+S_{7} .
\end{aligned}
$$

The parameters are defined by the following equations:

$$
\begin{aligned}
& g_{1}=\left(\Delta \varepsilon_{\theta}^{\mathrm{ch}} v_{\theta}+\Delta \varepsilon_{r}^{\mathrm{ch}}\right) E_{r}, \\
& g_{2}=\left(\Delta \varepsilon_{r}^{\mathrm{ch}} v_{r}+\Delta \varepsilon_{\theta}^{\mathrm{ch}}\right) E_{\theta}, \\
& S_{7}=\frac{g_{1} \beta^{2}\left(1+v_{r}\right)-g_{2}\left(1+\beta^{2} v_{r}\right)}{\left(1-v_{r} v_{\theta}\right)\left(1-\beta^{2}\right)}, \\
& S_{8}=\frac{g_{1}\left(v_{\theta}+\beta^{2}\right)-g_{2}\left(1+v_{\theta}\right)}{\left(1-v_{r} v_{\theta}\right)\left(1-\beta^{2}\right)} .
\end{aligned}
$$

3.3. Residual Stresses of the Composite Cylinder. Through the stress analysis in the above sections, the total stress $\sigma^{\text {total }}$ of the composite cylinder with mandrel is composed of stress $\sigma^{\mathrm{wt}}$, thermal stress $\sigma^{\mathrm{th}}$, and chemical shrinkage stress $\sigma^{\mathrm{ch}}$. It is well known that the wound components include two types: (1) for the composite cylinder with an inner liner, the liner is considered as the important part of the product. In this case, the inner liner is regarded as the mandrel. Therefore, the corresponding residual stress equals to the total stress $\sigma^{\text {total }}$. (2) For the composite cylinder after mandrel removal, the inner radius of the composite cylinder becomes a free surface 
TABLE 1: Fiber and resin mechanical properties.

\begin{tabular}{lccccc}
\hline & & \multicolumn{2}{c}{ Properties } \\
Epoxy & & Mandrel \\
\hline$E_{f}$ & Glass & $E_{c}^{0}$ & $4.6(\mathrm{MPa})$ & $E_{M}$ & $2.06 \times 10^{5}(\mathrm{MPa})$ \\
$v_{f}$ & $7.3 \times 10^{4}(\mathrm{MPa})$ & $E_{c}^{\infty}$ & $4.6 \times 10^{3}(\mathrm{MPa})$ & $v_{M}$ & 0.3 \\
$\alpha_{f}$ & 0.21 & $v_{c}$ & 0.3 & $a$ & $50 \mathrm{~mm}$ \\
$V_{f}$ & $4.9 \times 10^{-6}\left(1 /{ }^{\circ} \mathrm{C}\right)$ & $a_{r}$ & $8.2 \times 10^{-5}\left(1 /{ }^{\circ} \mathrm{C}\right)$ & $b$ & $6 \mathrm{~mm}$ \\
\hline
\end{tabular}

TABLE 2: Epoxy resin kinetic parameters.

\begin{tabular}{lcc}
\hline$E_{a}(\mathrm{KJ} / \mathrm{mol})$ & $A\left(\mathrm{~s}^{-1}\right)$ & $n$ \\
\hline 67.4 & $2.2 \times 10^{4}$ & 1.2 \\
\hline
\end{tabular}

and the radial stress vanishes. In this situation, the negative of the existing radial stress in the first layer is used as an internal pressure on the inner surface. The stress in the composite cylinder resulting from this internal stress is superimposed on the existing stress state in the layers. The solution can be calculated by choosing the constants in (10a) and (10b) to match the boundary conditions $\sigma_{r M}=-\sigma_{r 1}^{\text {total }}$ at $r=b$ and $\sigma_{r M}=0$ at $r=r_{n}$. It can be expressed as

$$
\begin{aligned}
& \sigma_{r M}(x)=\frac{m^{\beta-1} \sigma_{r 1}^{\text {total }}}{m^{2 \beta}-1}\left[\left(\frac{x}{m}\right)^{\beta-1}-\left(\frac{m}{x}\right)^{\beta+1}\right], \\
& \sigma_{\theta M}(x)=\frac{m^{\beta-1} \sigma_{r 1}^{\text {total }}}{m^{2 \beta}-1}\left[\frac{S_{3}}{S_{1}}\left(\frac{x}{m}\right)^{\beta-1}+\frac{S_{4}}{S_{2}}\left(\frac{m}{x}\right)^{\beta+1}\right],
\end{aligned}
$$

where $\sigma_{r 1}^{\text {total }}$ is the total radial stress of the first layer in the composite cylinder with mandrel. Thus, the residual stresses of the composite cylinder are obtained by adding this stress to the total stress $\sigma^{\text {total }}$. Then, the residual stresses are written as follows:

$$
\begin{aligned}
& \sigma_{r}^{\mathrm{Rs}}(x)=\sigma_{r}^{\text {total }}(x)+\sigma_{r M}(x), \\
& \sigma_{\theta}^{\mathrm{Rs}}(x)=\sigma_{\theta}^{\text {total }}(x)+\sigma_{\theta M}(x) .
\end{aligned}
$$

\section{Model Verification}

4.1. Material and Parameter Setting. In order to verify the accuracy of the developed model, the experimental investigation is performed to compare with the numerical analysis. The material selected in this study is the glass/epoxy prepreg tape. The parameters are listed in Table 1. Epoxy resin kinetic parameters are listed in Table 2 . In the manufacturing process, the winding temperature and environment temperature are $50^{\circ} \mathrm{C}$ and $16^{\circ} \mathrm{C}$. The winding tension and pressure of hot compaction roller are set to $6.8 \mathrm{~N} / \mathrm{mm}$ and $1000 \mathrm{~N}$. The curing temperature is $174^{\circ} \mathrm{C}$, the volumetric shrinkage of the epoxy resin is $1 \%$, the winding pattern adopts hoop winding, the total number of layers is 70 , and the thickness of the woven prepreg tape is set to $0.25 \mathrm{~mm}$.

4.2. Sample Preparation. The test specimen is fabricated by the robot winding machine as shown in Figure 4. The positional accuracy is controlled by the Kuka robot system, and the mandrel is rotated at $5 \mathrm{rpm}$ to wrap the prepreg tape. In addition, the process parameters such as winding tension, temperature, and pressure are controlled by SIMATIC S71200 PLC. In the curing process, it is well known that the stiffness of composite is affected by the instantaneous temperature of the composite cylinder. In order to measure the variation of instantaneous temperature, the thermocouples are embedded into the interlayer when the prepreg tape is wrapped on the mandrel. The thermocouples are linked to the multichannel temperature acquisition unit (ADAM4118). The temperature data are collected and saved by the upper computer through the RS-485 bus.

4.3. Measurement Method. In this experiment, a widely used slitting method is adopted to measure the actual residual stresses [28]. The method measures a relative hoop strain either on the inner surface or on the outer surface caused by the relief of the residual hoop stress on the slitting section of the composite cylinder. The approach assumes that the cut cylinder can be returned to its original shape by a pure moment. Thus, the residual stresses are equated as the stresses in the cut cylinder using curved beam bending theory. For the composite cylinder with homogeneous material, the residual stresses are written as follows [28, 29]:

$$
\begin{aligned}
& \sigma_{\theta}=-\frac{4 M_{\mathrm{r}}}{\left(b^{2}-a^{2}\right)^{2}-4 a^{2} b^{2}(\log (b / a))^{2}}\left(\frac{-a^{2} b^{2}}{r^{2}} \log \frac{b}{a}+b^{2} \log \frac{r}{b}+a^{2} \log \frac{a}{r}+b^{2}-a^{2}\right) \\
& \sigma_{r}=-\frac{4 M_{\mathrm{r}}}{\left(b^{2}-a^{2}\right)^{2}-4 a^{2} b^{2}(\log (b / a))^{2}}\left(\frac{a^{2} b^{2}}{r^{2}} \log \frac{b}{a}+b^{2} \log \frac{r}{b}+a^{2} \log \frac{a^{2}}{r}\right)
\end{aligned}
$$

where $a$ and $b$ are inner and outer radius of the cylinder and $M_{r}$ is the residual moment per width.
The opposite residual moment $-M_{r}$ can be calculated from the boundary conditions of (34) at the inner surface 


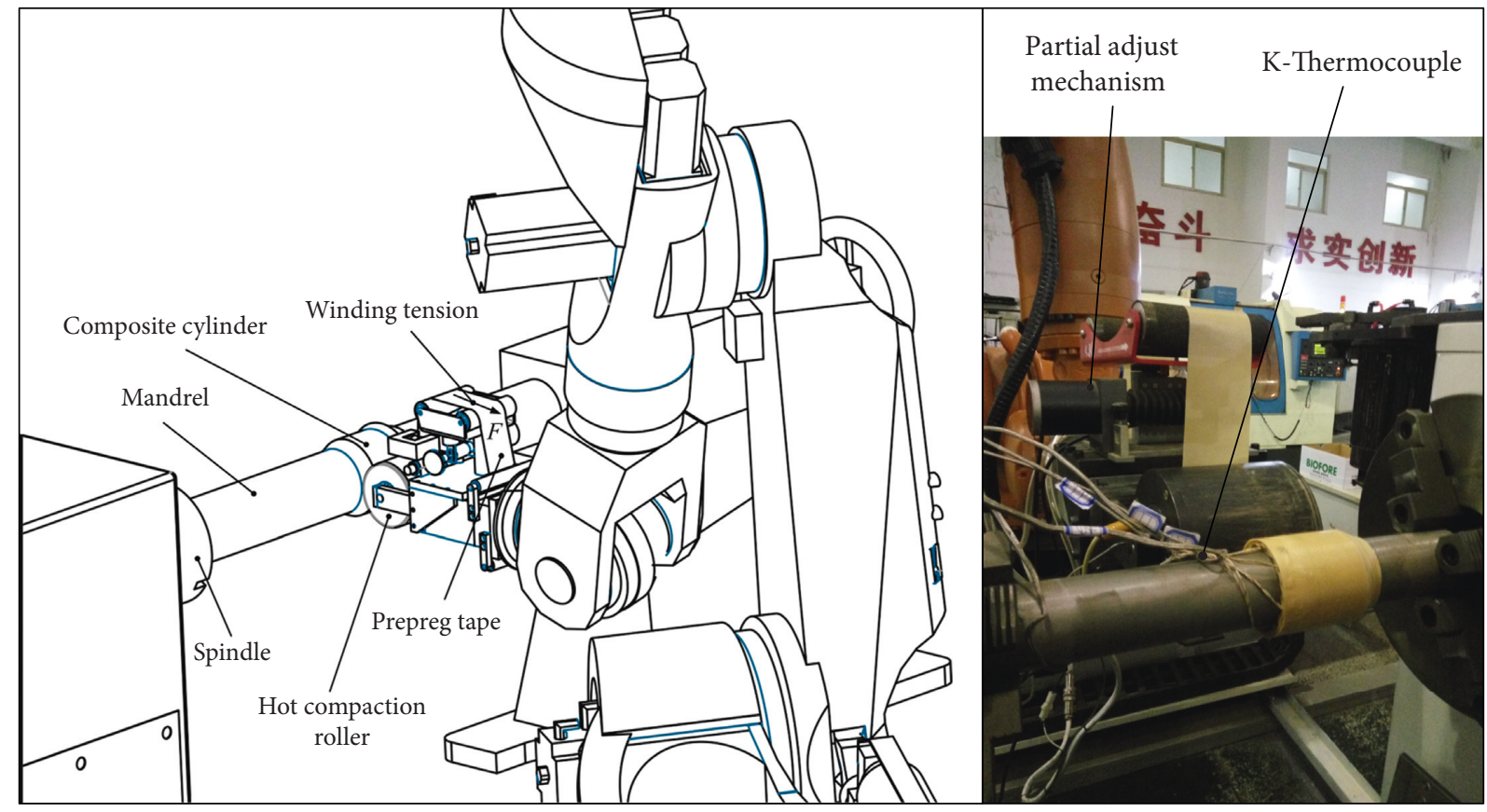

FIgURE 4: Composite cylinder fabricated by a robotic winding machine.

or the outer surface where the relative hoop strain was measured during the slitting operation. The boundary conditions are expressed as one of the following equations [29]:

$$
\begin{gathered}
\sigma_{\theta}(a)=E_{\theta} \Delta \varepsilon_{a}, \\
\sigma_{\theta}(b)=E_{\theta} \Delta \varepsilon_{b},
\end{gathered}
$$

where $\Delta \varepsilon_{a}$ and $\Delta \varepsilon_{b}$ are the measured relative hoop strains on the inner and outer surfaces and $E_{\theta}$ is the elastic constant.

4.4. Results and Discussion. In order to verify the residual stresses of the composite cylinder after mandrel removal, the residual stress distribution of the composite wound cylinder with an inner liner should be calculated first based on the model. The numerical results are shown in Figure 5. The residual radial stress increases as the radial coordinate is increased from the inner radius to outer radius. The maximum value of the compressive stress occurs at the inner radius. Similar to the radial stress, the maximum value of the corresponding hoop stress is also at the inner radius, and the hoop stress is tensile. Moreover, these stresses are more than one order of magnitude higher than those in the radial direction.

In this investigation, the strain gages were mounted on the center of inner surface in the hoop direction. The opposite side of gage was cut along the radial line by a hacksaw as shown in Figure 6 . When the $-M_{r}$ was large to close the cylinder, another cut was performed to remove a small slice of the composite cylinder so that the slitting section was free. After the composite cylinder was separated from the clamping fixture, the hoop strain was measured during the slitting experiment. Considering end face of slit maybe touch, the slice was set to $5 \mathrm{~mm}$. The

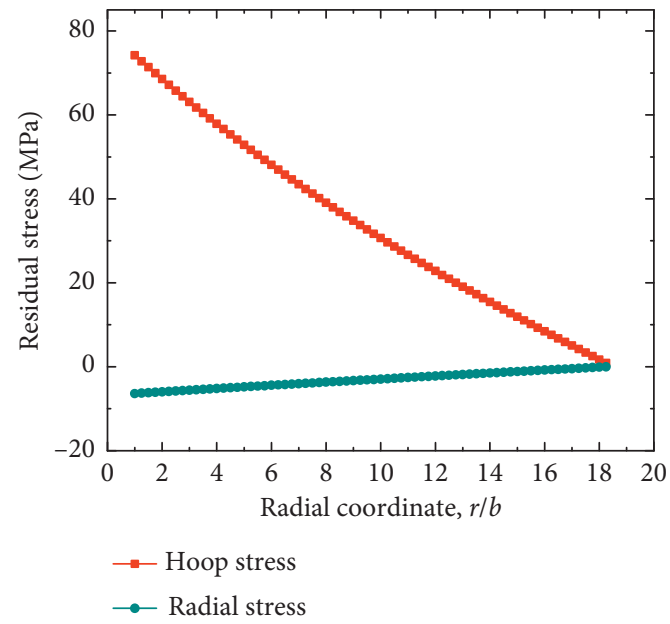

FIgURE 5: Residual stress distribution of the composite cylinder with an inner liner.

experimental result shows that the composite cylinder was closed, and the change of displacement was about $2.1 \mathrm{~mm}$. The value of measured strain on the inner surface was -701 microstrain $(\mu \mathrm{m} / \mathrm{m})$. Based on (34) and (35), the residual moment $M_{r}$ can be obtained, and its value is $1401 \mathrm{~N}$. Then, the residual stresses measured by the slitting method can be obtained based on (34). The values are shown in Figures 7 and 8. Based on the simulated results in Figure 5, the corresponding numerical results of residual stresses can be calculated according to (33) after the mandrel is removed.

Figure 7 displays the comparison of the residual hoop stress in the composite wound cylinder after mandrel removal between the experimental results and the predicted 

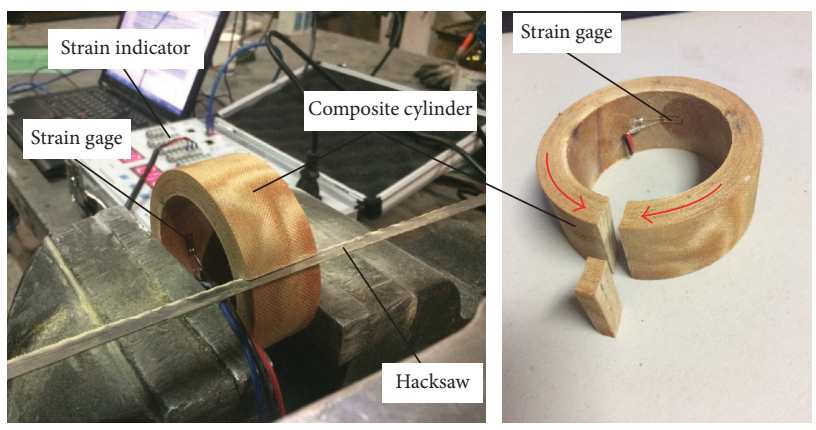

Figure 6: A slitting experiment for measuring residual stress.

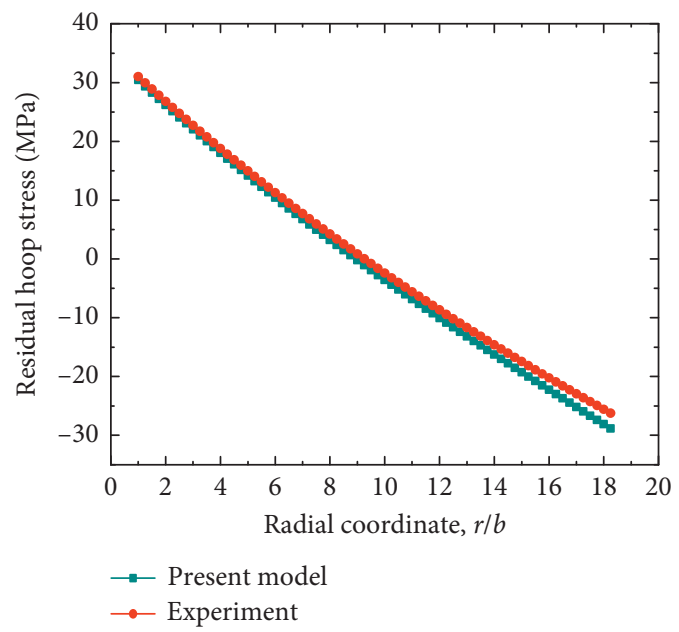

FIGURE 7: Residual hoop stress of the composite wound cylinder after mandrel removal.

values. As shown in Figure 7, the maximum values in the experiment and model occur at the boundaries, where maximum tension at the inner radius and maximum compression at the outer radius. The maximal difference of hoop stress is $2.60 \mathrm{MPa}$ which occurs at the outer radius, and the error is $9.0 \%$. The results of model are basically consistent with the theoretical values. The residual radial stresses are shown in Figure 8. The distribution of the radial stress is similar to a sine wave with zero values at the boundaries. These stresses are tensile and low in magnitude, and the maximum value is around the neutral axis. The maximal difference of radial stress between the model and experiment is $0.14 \mathrm{MPa}$, and the corresponding error is $7.7 \%$. It is observed that some discrepancies exist between the residual stresses calculated and measured in Figures 7 and 8, but the errors are still reasonable for predicting the residual stresses in engineering practice.

Compared with the residual stresses before mandrel removal as shown in Figure 5, the residual stresses after mandrel removal are lower in magnitude. Moreover, the radial stress distribution changes from compression to tension. The hoop stress varies from tension to both of tension and compression in the radial direction due to the stress reequilibrium.

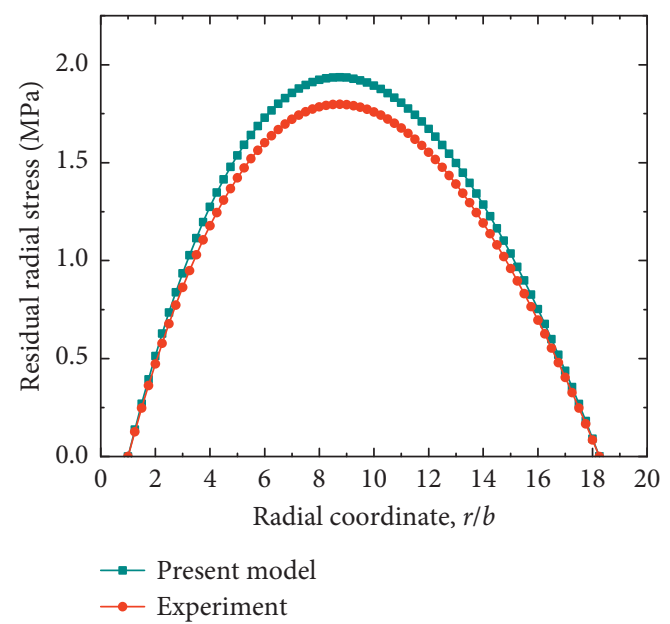

FIgURE 8: Residual radial stress of the composite wound cylinder after mandrel removal.

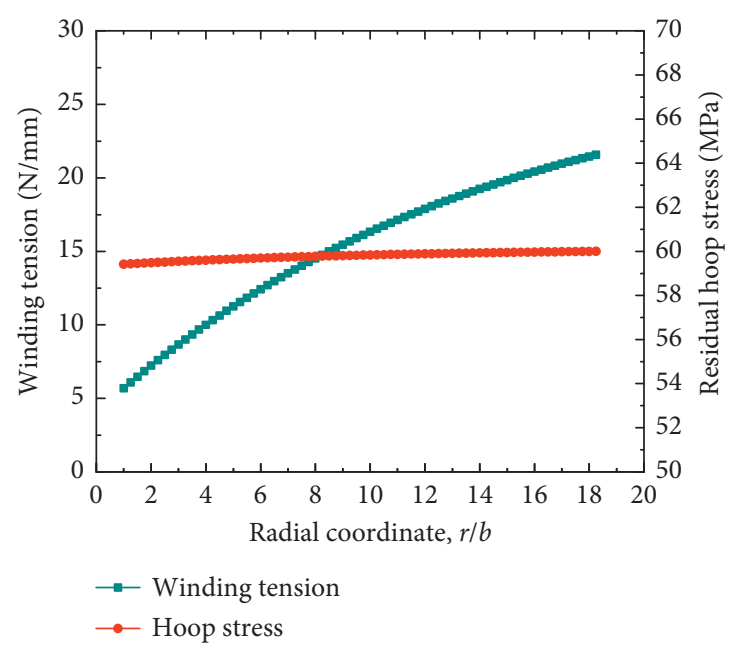

FIGURE 9: Designed winding tension and the corresponding residual hoop stress.

\section{Design of Winding Tension for the Composite Cylinder with an Inner Liner}

In order to fully exploit the strength of fiber [30] and prevent the wrinkle defect, the process parameters must be designed to ensure that the composite cylinder with an inner liner has a uniform residual hoop stress through the filament wound section. In this study, the winding tension is regarded as the design object. The desired residual hoop stress of the composite cylinder with a liner is assumed as constant $S$. The residual radial stress can be expressed as follows:

$$
\sigma_{r}^{\mathrm{wh}}(x)+\sigma_{r}^{\mathrm{th}}(x)+\sigma_{r}^{\mathrm{ch}}(x)=-\frac{1}{x} \int_{x}^{m} S \mathrm{~d} x=-\frac{m-x}{x} S .
$$

Based on (16a), (16b), (26), (30), and (36) and inversely solving the analytic model, the winding tension can be derived as follows: 


$$
F(x)=h\left\{\left[1+\frac{H_{2} S_{3}(x)^{2 \beta}-H_{1} S_{4}}{H_{2} S_{1}(x)^{2 \beta}+H_{1} S_{2}} \frac{m-x}{x}\right] S-\left[\frac{H_{1} S_{4}-H_{2} S_{3} x^{2 \beta}}{H_{2} S_{1}(x)^{2 \beta}+H_{1} S_{2}}\left(\sigma_{r}^{\text {th }}+\sigma_{r}^{\mathrm{ch}}\right)+\left(\sigma_{\theta}^{\text {th }}+\sigma_{\theta}^{\mathrm{ch}}\right)\right]\right\} .
$$

Here, the residual radial stress can be determined by the residual hoop stress. Thus, the residual hoop stress is only considered to design the winding tension. The desired residual hoop stress $S$ is assumed as $60 \mathrm{MPa}$, and the values of process parameters mentioned in the previous section are adopted. In this study, the winding tension designed based on (37) is plotted in Figure 9. As depicted, the winding tension rises gradually as the radial coordinate is increased from the inner radius to outer radius. Figure 9 also shows the corresponding numerical result of the hoop stress. The residual hoop stress increases steadily to $60 \mathrm{MPa}$ along the radial direction. Moreover, the minimum residual hoop stress is $59.4 \mathrm{MPa}$ which satisfies the desired value within $1 \%$ of error. The result indicates that the method can be adopted to adjust the residual hoop stress through changing the winding tension along the thickness of the composite cylinder.

\section{Conclusion}

The residual stresses of the composite wound cylinder are highly sensitive to the winding and curing process. Based on the plane stress assumption, the analytic method is addressed to investigate the stress state of the composite cylinder. The results could be drawn as follows:

(1) Based on the winding and curing process, the analytical model of residual stresses is established. This model can be applied to analyze the stress state of the composite cylinder before and after mandrel removal.

(2) The variations of shrinkage strains and coefficient of thermal expansion are introduced to develop the residual stresses model. The numerical simulation and slitting experiment for the composite wound cylinder after mandrel removal are investigated. The analysis reveals that the maximal difference of radial stress between the model and experiment is $0.14 \mathrm{MPa}$ around the neutral axis. The maximal difference of hoop stress is $2.6 \mathrm{MPa}$ which occurs at the outer radius. Besides, the corresponding errors of hoop and radial stress at the maximal difference positions are $9.0 \%$ and $7.7 \%$, respectively. The result indicates that the present model can be used to predict the residual stresses.

(3) The design method of the winding tension is proposed according to the residual stresses model. To obtain the desired residual hoop stress of the composite wound cylinder with an inner liner, the designed winding tension is determined through inverting the residual stresses model. The numerical analysis is performed, and the maximum error was less than $1 \%$. The result indicates that the method is feasible to design the winding tension.

(4) The residual stress profile of the composite wound cylinder can be calculated conveniently by adopting the present model since the specific formulas of stresses induced in the whole process have been given. In addition, the winding tension designed based on the present model can be obtained directly rather than using iteration or search algorithm.

\section{Conflicts of Interest}

The authors declare that they have no conflicts of interest.

\section{Acknowledgments}

This work was supported by the National Natural Science Foundation of China (Grant no. 51375394).

\section{References}

[1] B. Jiang, S. He, Y. D. Huang, and H. T. Pan, "Investigation of the kinetics of curing reaction for the resin matrix polymer composite based on near-infrared spectroscopy," Applied Spectroscopy Reviews, vol. 50, no. 8, pp. 627-640, 2015.

[2] A. Kojima and S. Furukawa, "Recycling of resin matrix composite materials VII: future perspective of FRP recycling," Advanced Composite Materials, vol. 6, no. 3, pp. 215-225, 1997.

[3] J. Q. Amado, "Manufacture and testing of lightweight tubes for rocketry and centrifuges," Lightweight Composite Structures in Transport: Design, Manufacturing, Analysis and Performance, pp. 421-438, 2016.

[4] Y. Y. Shi, H. Tang, and Q. Yu, "Key technology of the NC tapewinding machine," Acta Aeronautica et Astronautica Sinica, vol. 29, no. 1, pp. 233-239, 2008.

[5] P. P. Parlevliet, H. E. Bersee, and A. Beukers, "Residual stresses in thermoplastic composites-a study of the literature. Part III: effects of thermal residual stresses," Composites Part A: Applied Science and Manufacturing, vol. 38, no. 6, pp. 1581-1596, 2007.

[6] K. L. Thunhorst, A. M. Hine, P. Sedgwick et al., Nanosilica Concentration Effect on Epoxy Resins and Filament Wound Composite Overwrapped Pressure Vessels, Society for the Advancement of Material and Process Engineering, Long Beach, CA, USA, 2011.

[7] N. H. Mostafa, Z. N. Ismarrubie, S. M. Sapuan et al., "Fibre prestressed composites: theoretical and numerical modelling of unidirectional and plain-weave fibre reinforcement forms," Composite Structures, vol. 159, pp. 410-423, 2017.

[8] S. Y. Lee and G. S. Springer, "Filament winding cylinders I. Process model," Journal of Composite Materials, vol. 24, no. 12, pp. 1270-1298, 1990.

[9] Z. Cai, T. Gutowski, and S. Allen, "Winding and consolidation analysis for cylindrical composite structures," Journal of Composite Materials, vol. 26, no. 9, pp. 1374-1399, 1992.

[10] E. A. Kempner and H. T. Hahn, "Effect of radial stress relaxation on fibre stress in filament winding of thick composites," Composites Manufacturing, vol. 6, no. 2, pp. 67-77, 1995.

[11] J. A. Guemes, "Curing residual stresses and failure analysis in composite cylinders," Journal of Reinforced Plastics and Composites, vol. 13, no. 5, pp. 408-419, 1994.

[12] M. A. Stone, I. F. Schwartz, and H. D. Chandler, "Residual stresses associated with post-cure shrinkage in GRP tubes," Composites Science \& Technology, vol. 57, no. 1, pp. 47-54, 1997. 
[13] C. Kim and S. R. White, "Continuous curing and induced thermal stresses of a thick filament wound composite cylinder," Journal of Reinforced Plastics and Composites, vol. 20, no. 2, pp. 166-180, 2001.

[14] A. S. Kaddour, S. T. S. Al-Hassani, and M. J. Hinton, "Residual stress assessment in thin angle ply tubes," Applied Composite Materials, vol. 10, no. 3, pp. 169-188, 2003.

[15] H. Lu, M. Schlottermuller, N. Himmel et al., "Effects of tape tension on residual stress in thermoplastic composite filament winding," Journal of Thermoplastic Composite Materials, vol. 18, no. 6, pp. 469-487, 2005.

[16] J. Li, C. Dong, and S. Chen, "Consolidation and warpage deformation finite element analysis of filament wound tubes," Applied Composite Materials, vol. 16, no. 5, pp. 307-320, 2009.

[17] M. Schlottermuller, H. Lu, Y. Roth et al., "Thermal residual stress simulation in thermoplastic filament winding process," Journal of Thermoplastic Composite Materials, vol. 16, no. 6, pp. 497-519, 2003.

[18] C. Dedieu, A. Barasinski, F. Chinesta, and J.-M. Dupillier, "About the origins of residual stresses in in situ consolidated thermoplastic composite rings," International Journal of Material Forming, vol. 10, no. 5, pp. 779-792, 2016.

[19] J. W. Kim, J. H. Lee, H. G. Kim, H. S. Kim, and D. G. Lee, "Reduction of residual stresses in thick-walled composite cylinders by smart cure cycle with cooling and reheating," Composite Structures, vol. 75, no. 1, pp. 261-266, 2006.

[20] D. H. Lee, S. K. Kim, W. I. Lee, S. K. Ha, and S. W. Tsai, "Smart cure of thick composite filament wound structures to minimize the development of residual stresses," Composites Part A: Applied Science and Manufacturing, vol. 37, no. 4, pp. 530-537, 2006.

[21] M. F. Ren, C. L. Zheng, and H. R. Chen, "Iterative search for the isotension design of the band wound vessels with liner," Acta Materiae Compositae Sinica, vol. 21, no. 5, pp. 153-158, 2004.

[22] D. H. Wu and Z. Y. Zhang, "Approach to design tension of filament winding for thick composite pipes using a neural network," Fuhe Cailiao Xuebao (Acta Materiae Compositae Sinica), vol. 29, no. 4, pp. 195-203, 2012.

[23] J. Z. Xu, Y. N. Miao, M. Qiao, and S. Li, "Tension design of heated-mandrel winding process based on analytical algorithm," Journal of Reinforced Plastics and Composites, vol. 33, no. 16, pp. 1529-1541, 2014.

[24] T. A. Bogetti and J. W. Gillespie, "Process-induced stress and deformation in thick-section thermoset composite laminates," Journal of Composite Materials, vol. 26, no. 5, pp. 626-660, 1992.

[25] C. X. Liu, J. Z. Xing, L. Chen et al., “Analysis of residual winding tension and design of winding tension for hoop winding on flexible cylinder," Journal of Solid Rocket Technology, vol. 36, no. 2, pp. 261-265, 2013.

[26] M. L. Costa, E. C. Botelho, J. M. F. Paiva et al., "Characterization of cure of carbon/epoxy prepreg used in aerospace field," Materials Research, vol. 8, no. 3, pp. 317-322, 2005.

[27] J. M. Svanberg and J. A. Holmberg, "Prediction of shape distortions. Part II. Experimental validation and analysis of boundary conditions," Composites Part A: Applied Science and Manufacturing, vol. 35, no. 6, pp. 723-734, 2004.

[28] S. P. Timoshenko and J. Goodier, Theory of Elasticity, McGrawHill Book Co., Inc., New York, USA, 3rd edition, 1970.

[29] J. W. Kim and D. G. Lee, "Measurement of residual stresses in thick composite cylinders by the radial-cut-cylinder-bending method," Composite Structures, vol. 77, no. 4, pp. 444-456, 2007.

[30] X. S. Yi, S. Y. Du, and L. T. Zhang, Composite Handbook, Chemical Industry Press, Beijing, China, 1st edition, 2009. 


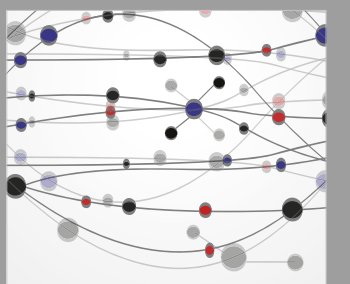

The Scientific World Journal
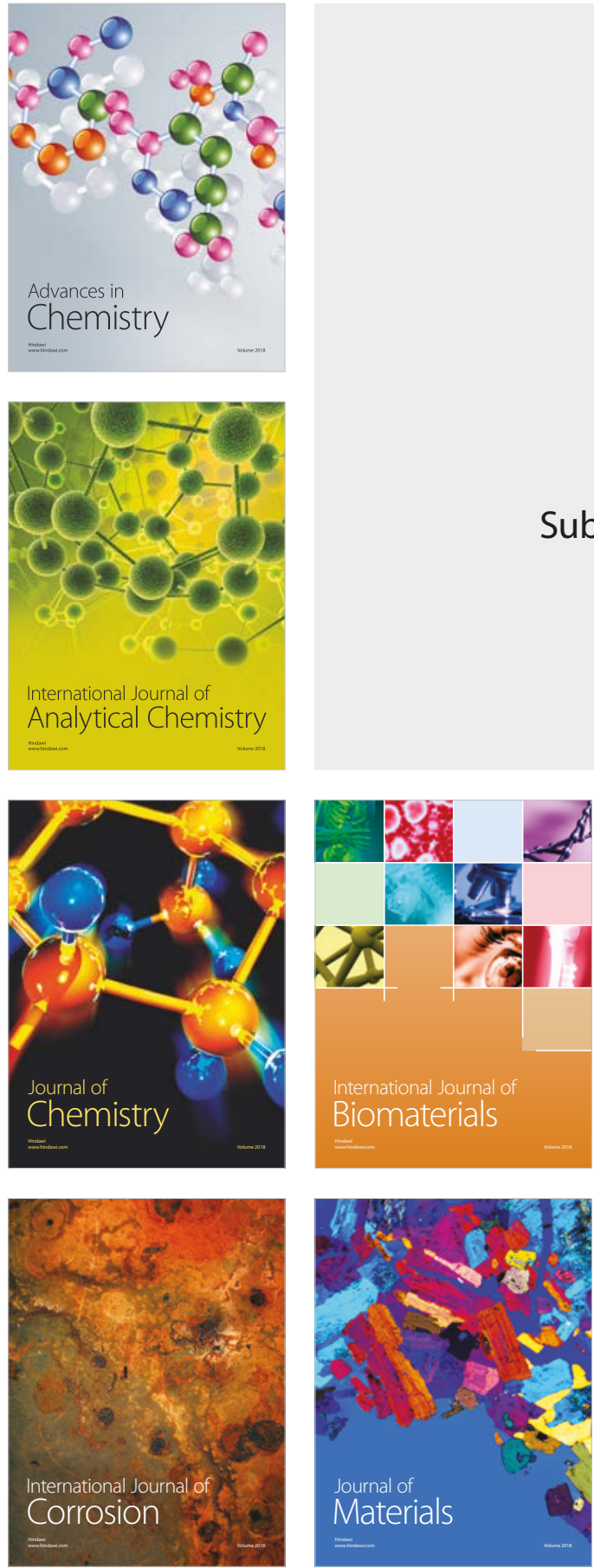

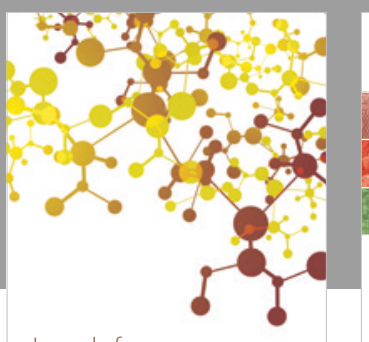

Journal of

Applied Chemistry
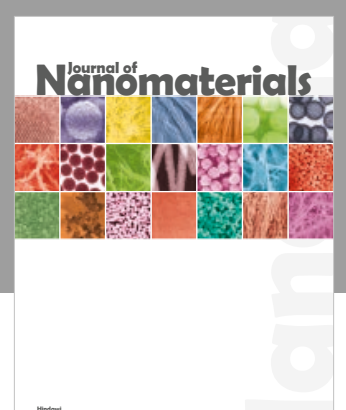

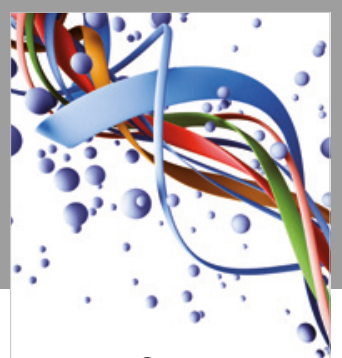

Scientifica

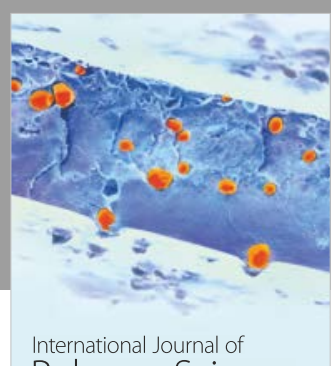

Polymer Science

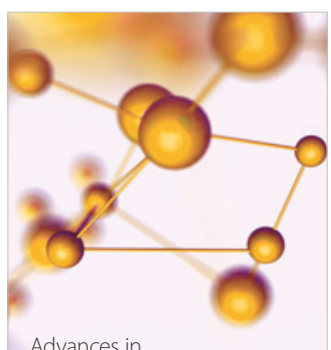

Physical Chemistry
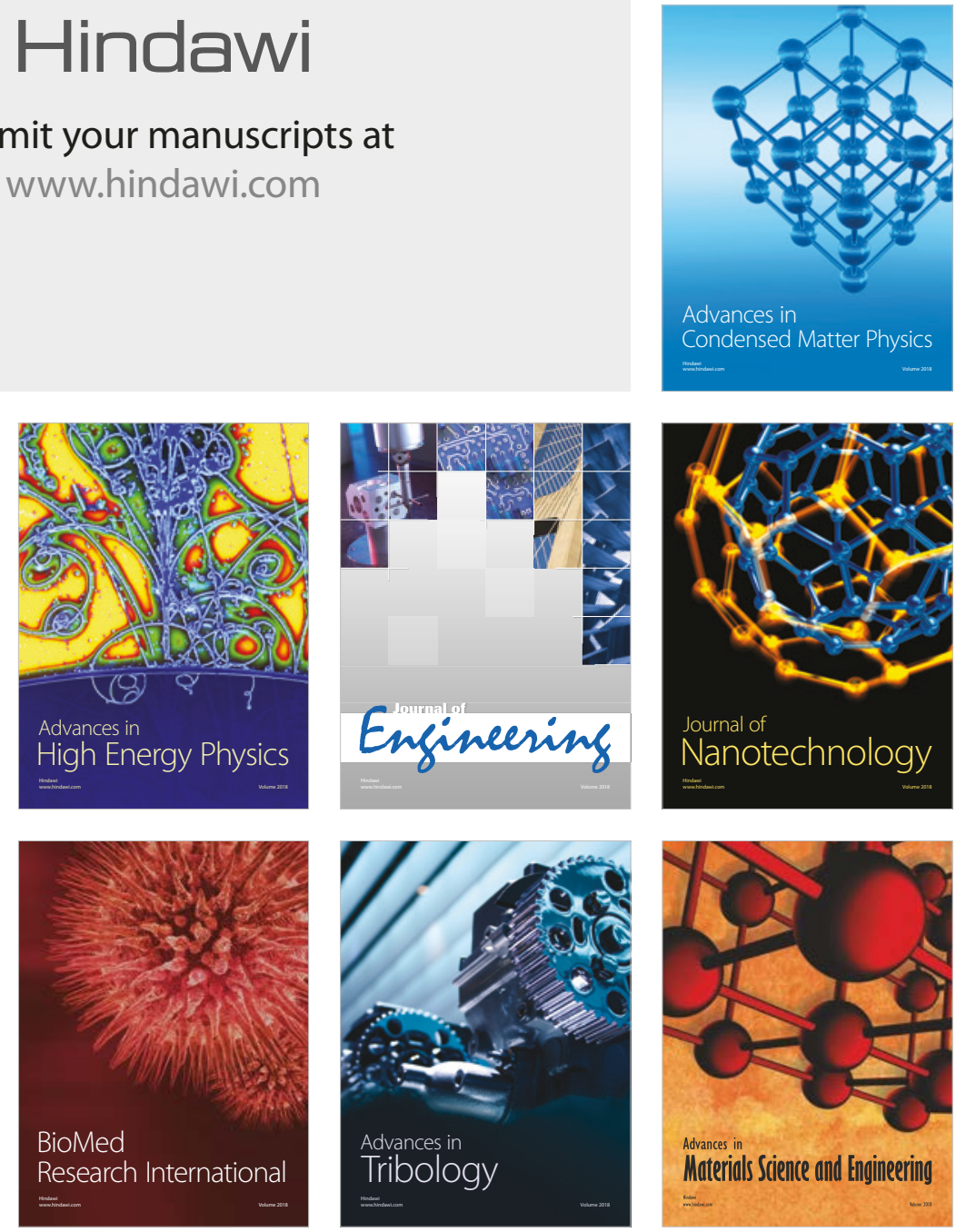